\title{
SCIENTIFIC REPORTS

\section{Environmental fungi and bacteria facilitate lecithin decomposition and the transformation of phosphorus to apatite}

\author{
Chunkai Li ${ }^{1}$, Qisheng $\mathrm{Li}^{1}$, Zhipeng Wang ${ }^{1}$, Guanning $\mathrm{Ji}^{1}$, $\mathrm{He} \mathrm{Zhao}^{1}$, Fei Gao ${ }^{1}, \mathrm{Mu} \mathrm{Su}^{1}$, \\ Jiaguo Jiao ${ }^{1,2^{*}}$, Zhen $\mathrm{Li}^{1}{ }^{1,3^{*}}$ \& Huixin $\mathrm{Li}^{1,2}$
}

Organophosphorus compounds (OP) are stable $\mathrm{P}$ source in nature, and can increase eutrophication risk in waterbodies. Lecithin was the most difficult OP to be broken down. In this study, two typical phosphate-solubilizing microorganisms, Aspergillus niger and Acinetobacter sp., were applied to evaluate their ability to decompose both inorganic phosphates and lecithin. A. niger and Acinetobacter sp. could solubilize calcium phosphates by secreting various organic acids, e.g., oxalic and formic acids. The fungus, $A$. niger, shows significantly higher ability of solubilizing these inorganic phosphates than Acinetobacter sp., primarily due to its secretion of abundant oxalic acid. However, the bacterium, Acinetobacter sp., could secrete more acid phosphatase than $A$. niger for lecithin decomposition, i.e., 9300 vs. $8500 \mu \mathrm{mol} \mathrm{L}^{-1} \mathrm{~h}^{-1}$. Moreover, after addition of $\mathrm{CaCl}_{2}$, the released $\mathrm{P}$ from lecithin was transformed to stable chlorapatite in the medium. To the contrast, Ca cations inclined to form calcium oxalate (rather than stable phosphate mineral) after the incubation of $A$. niger, as it induced relatively acidic environment after breaking down lecithin. Therefore, this work sheds light on the bright future of applying bacteria and Ca cations in OP pollutant management.

Phosphorus (P) derived from organophosphorus (OP) compounds constitutes 30 to $90 \%$ of the total P content in soil ${ }^{1}$. OP compounds are widely distributed in soil and appear as various forms, such as inositol phosphates, phospholipids, and nucleic acids ${ }^{2}$. However, most OP compounds in soil exist as insoluble forms, and only a small fraction $(<1 \%)$ can be directly used by crops ${ }^{3}$. OP species, usually derived from the decomposition of aquatic organisms, increase the risk of eutrophication ${ }^{4,5}$. The efficient use of $\mathrm{P}$ and the remediation of P-induced eutrophication require a better understanding of biogeochemistry of OP compounds.

It is critical that phospholipids be transformed into soluble $\mathrm{P}$, as OP compounds are more resistant to decay than are phytates and nucleic acids. The degradation of phospholipids to inorganic phosphate is regulated by phosphatases $^{6}$, including two major types: phosphodiesterase (PDE) and phosphomonoesterase (PME) ${ }^{7}$. Many physical and chemical techniques have been applied to oxidise or break down phospholipids, including UV-LED/ $\mathrm{TiO}_{2}$ photocatalytic/photoelectrocatalytic inactivation, acid-based hydrolysis, and graphene oxide-catalytic hydrolysis ${ }^{8-10}$. Soluble $\mathrm{P}$ originated from orthophosphates could also react with $\mathrm{Pb}^{2+}, \mathrm{Ca}^{2+}, \mathrm{Mg}^{2+}$, or $\mathrm{Fe}^{3+}$ cations to form minerals such as hydroxylapatite, struvite, or zwieselite, respectively ${ }^{11-16}$. However, the potential pathways of OP decomposition and $\mathrm{P}$ mineralization regulated by microorganisms are still poorly known.

Phosphate-solubilizing microorganisms (PSMs) are plant growth-promoting microorganisms that have traditionally been used to increase crop yields and improve nutrient levels in soil ${ }^{17,18}$. PSMs contribute to $P$ release from both inorganic and organic matters. Solubilisation of (inorganic) phosphate involves the secretion of low molecular weight organic acids (LMWOAs) by PSMs ${ }^{19,20}$. The two major categories of PSMs are phosphate-solubilizing bacteria (PSB) and phosphate-solubilizing fungi (PSF) ${ }^{21-23}$. PSB include Acinetobacter sp., Pseudomonas aeruginosa, Alcaligenes faecalis, Sphingobium sp., Pantoea agglomerans, Rahnella aquatilis, Enterobacter sp., Burkholderia cepacia, and Bacillus sp. ${ }^{24-28}$. PSF also possess a remarkable ability to solubilise phosphate, including Aspergillus

\footnotetext{
${ }^{1}$ College of Resources and Environmental Sciences, Nanjing Agricultural University, Nanjing, Jiangsu, 210095, China. 2Jiangsu Collaborative Innovation Center for Solid Organic Waste Resource Utilization, Nanjing, Jiangsu, 210014, China. ${ }^{3}$ Jiangsu Provincial Key Lab for Organic Solid Waste Utilization, Nanjing Agricultural University, Nanjing, 210095, China. *email: jiaguojiao@njau.edu.cn; lizhen@njau.edu.cn
} 


\begin{tabular}{|l|l|l|l|l|}
\hline \multirow{2}{*}{$\begin{array}{l}\text { Phosphorus } \\
\text { sources }\end{array}$} & \multicolumn{2}{|l|}{ A. niger } & \multicolumn{2}{l|}{ Acinetobacter sp. } \\
\cline { 2 - 5 } & $\mathbf{p H}$ & $\begin{array}{l}\text { Soluble P concentration } \\
\left(\mathbf{m g ~ L}^{-1}\right)\end{array}$ & $\mathbf{p H}$ & \begin{tabular}{l} 
Soluble P concentration $_{\left(\mathbf{m g ~ L}^{-1}\right)}$ \\
\hline TCP
\end{tabular} \\
\hline FAp & $3.5 \pm 0.1^{\mathrm{a}} \mathrm{a}^{\mathrm{b}}$ & $770.5 \pm 21.7 \mathrm{a}$ & $4.2 \pm 0.0 \mathrm{~b}$ & $402.3 \pm 11.0 \mathrm{a}$ \\
\hline
\end{tabular}

Table 1. The highest levels of soluble P released by A. niger and Acinetobacter sp. detected after five-days incubation. TCP and FAp were added to the PVK medium as a P source. ${ }^{a}$ Data were listed as mean \pm S.E. balues followed by different letter $(\mathrm{a}-\mathrm{b})$ in the column are significantly different according to a Duncan's Multiple Range Test at $\mathrm{P}<0.05$.

niger, Penicillium, Curvularia, and Trichoderma ${ }^{29,30}$. PSF usually have higher phosphate-solubilizing ability than $\mathrm{PSB}^{31,32}$. A. niger and Acinetobacter sp. function as the representative PSF and PSB, respectively ${ }^{25,33,34}$. Both A. niger and Acinetobacter synthesize and secrete phosphatase and phytase under P-deficient conditions, in addition to their secretion of organic acids ${ }^{35,36}$. However, few studies have examined the differences in the abilities to solubilize inorganic phosphates and break down OP compounds between PSB and PSF.

Lecithin, a model phospholipid, has amphiphilic and surface-active characteristics. It is commonly used in food, cosmetics, and pharmaceutical industries as a co-surfactant or emulsion ${ }^{9,37}$. Lecithin also functions as a biogenic mobilizing agent that is commonly used to wash sand contaminated with fuel oil ${ }^{38}$. Both natural and anthropogenic processes increase levels of lecithin. The excessive accumulation of lecithin in soil and water could stimulate the overgrowth of algae and increase the risk of eutrophication ${ }^{4,39,40}$. Lecithin is decomposed only under extreme physical/chemical conditions, e.g., high temperature, extreme $\mathrm{pH}$, dehydration, freezing, chilling, and high mineral concentrations ${ }^{41,42}$. Therefore, it is necessary to develop eco-friendly strategies to control lecithin levels.

In this study, we compared the abilities of Acinetobacter (PSB) and A. niger (PSF) to break down lecithin. We also investigated the mineralization of the released $\mathrm{P}$ from lecithin. To identify the formation and composition of secondary minerals, we performed scanning electron microscopy (SEM) and energy dispersive spectroscopy (EDS) analyses.

\section{Results}

P Release from inorganic phosphates. A. niger increased the soluble $\mathrm{P}$ concentration in tricalcium phosphate (TCP)-amended PVK medium to $770.5 \mathrm{mg} \mathrm{L}^{-1}$ after incubation (Table 1). Accordingly, the $\mathrm{pH}$ of the medium in the presence of $A$. niger decreased to 3.5 (Table 1). As fluorapatite (FAp) (with lower solubility) was used as the $\mathrm{P}$ source, $A$. niger was still able to release soluble $\mathrm{P}$. However, the maximum soluble $\mathrm{P}$ concentration in FAp medium was significantly lower $\left(4.2 \mathrm{mg} \mathrm{L}^{-1}\right)$ than when TCP was used as a P source. In addition, the $\mathrm{pH}$ of the medium decreased to 3.1 (Table 1).

Acinetobacter sp. was less able to solubilize inorganic phosphates (from both TCP and FAp) than A. niger. In TCP medium, Acinetobacter sp. increased the soluble $\mathrm{P}$ concentration to $402.3 \mathrm{mg} \mathrm{L}^{-1}$ after five-days incubation. Accordingly, the $\mathrm{pH}$ of the medium $\mathrm{pH}$ decreased to 4.2, which was higher than that of medium containing $A$. niger (Table 1). The ability to release soluble P significantly decreased to $0.9 \mathrm{mg} \mathrm{L}^{-1}$ when FAp as $\mathrm{P}$ source, and the $\mathrm{pH}$ of the medium was close to neutral (Table 1).

LMWOAs secreted by PSMs. A. niger secreted approximately 565.2 and $150.4 \mathrm{mg} \mathrm{L}^{-1}$ formic acid when TCP and FAp were used as $\mathrm{P}$ sources, respectively (Fig. 1A). A. niger also produced oxalic acid at levels of $41.0 \mathrm{mg} \mathrm{L}^{-1}$ in TCP medium and $24.9 \mathrm{mg} \mathrm{L}^{-1}$ in FAp medium (Fig. 1B). Oxalic acid is the primary compound secreted by $A$. niger. However, the oxalic acid concentration was extremely low in the presence of $A$. niger (Fig. 1B), probably due to the formation of calcium oxalate ${ }^{34}$.

Formic acid, a primary LMWOA, was present at relatively high concentrations containing Acinetobacter sp.; Acinetobacter sp. secreted 170.4 and $46.5 \mathrm{mg} \mathrm{L}^{-1}$ formic acid when TCP and FAp were used as P sources, respectively (Fig. 1A). However, the oxalic acid concentration in the medium was significantly lower in the presence of Acinetobacter sp. versus A. niger when either TCP or FAp was used as a P source (Fig. 1B). By contrast, the concentration of LMWOAs secreted by Acinetobacter sp. was always lower than that of A. niger (Fig. 1A,B).

PSM - mediated lecithin breakdown. A. niger increased the soluble P concentration to $35.7 \mathrm{mg} \mathrm{L}^{-1}$ (17.9\% of lecithin phosphorus) after five-days incubation (Table 2). We detected an obvious increase in soluble $\mathrm{P}$ concentrations beginning on the second day of incubation, which raised to $23.1 \mathrm{mg} \mathrm{L}^{-1}$. However, the rate of release of soluble $\mathrm{P}$ from $A$. niger was relatively low. The soluble $\mathrm{P}$ concentration was slightly higher than $30 \mathrm{mg} \mathrm{L}^{-1}$ until the fifth day of incubation (Table 2). The $\mathrm{pH}$ of the medium exhibited a downward trend throughout the incubation period. The lowest $\mathrm{pH}$ was 4.6 on the fifth day of $A$. niger incubation (Table 2).

The soluble $\mathrm{P}$ concentration increased more rapidly in the presence of Acinetobacter sp. versus A. niger in the first three days of incubation, with the soluble $\mathrm{P}$ concentration in the medium reaching $30.6 \mathrm{mg} \mathrm{L}^{-1}$ (Table 2). In the presence of Acinetobacter sp., the soluble $\mathrm{P}$ concentration was elevated to $33.0 \mathrm{mg} \mathrm{L}^{-1}$ (16.5\% of lecithin - P) after four-days incubation (Table 2). The $\mathrm{pH}$ of the medium decreased slightly on the first day of incubation, reaching a minimum of 6.8. However, in contrast to $A$. niger, the $\mathrm{pH}$ of the medium in the presence of Acinetobacter sp. increased slightly during the subsequent period, reaching 7.0 on the third day of incubation (Table 2). 


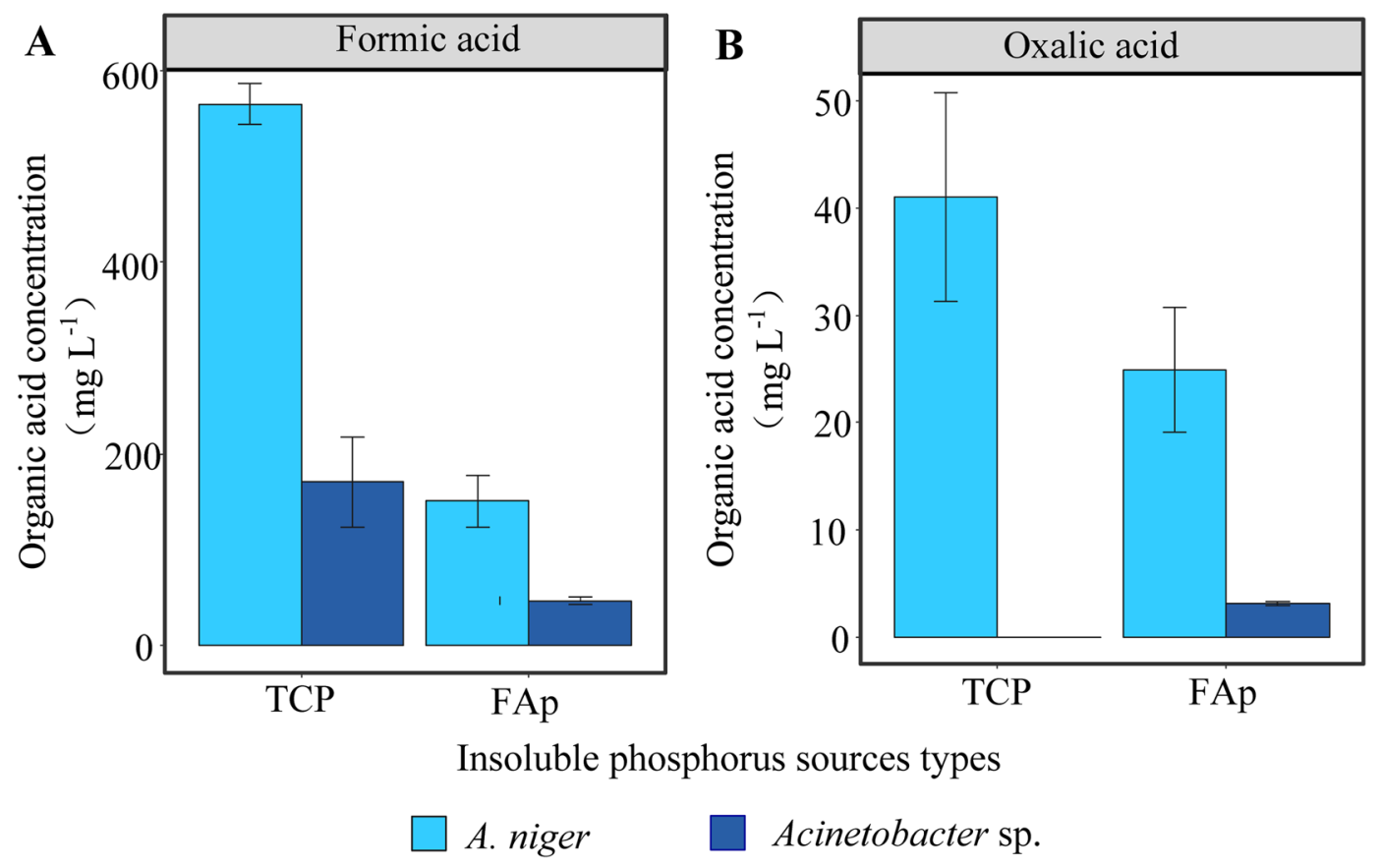

Figure 1. Concentrations of two major organic acids, formic acid (A) and oxalic acid (B), in medium containing A. niger and Acinetobacter sp. amended with TCP or FAp as a P source after five-days incubation. The columns show mean \pm S.E.

\begin{tabular}{|l|l|l|l|l|}
\hline \multirow{2}{*}{ Days } & \multicolumn{2}{|l|}{$\mathbf{p H}$} & \multicolumn{2}{l|}{ Soluble P concentration $\left(\mathbf{m g ~ L}^{-1}\right)$} \\
\cline { 2 - 5 } & A. niger & $\begin{array}{l}\text { Acinetobacter } \\
\text { sp. }\end{array}$ & A. niger & $\begin{array}{l}\text { Acinetobacter } \\
\text { sp. }\end{array}$ \\
\hline 0 & $7.6 \pm 0.1^{\mathrm{a}} \mathrm{a}^{\mathrm{b}}$ & $7.6 \pm 0.1 \mathrm{a}$ & $0.0 \pm 0.0 \mathrm{c}$ & $0.0 \pm 0.0 \mathrm{~d}$ \\
\hline 1 & $6.8 \pm 0.0 \mathrm{~b}$ & $6.8 \pm 0.0 \mathrm{c}$ & $0.1 \pm 0.1 \mathrm{c}$ & $3.2 \pm 0.7 \mathrm{c}$ \\
\hline 2 & $5.9 \pm 0.0 \mathrm{c}$ & $6.9 \pm 0.1 \mathrm{bc}$ & $23.1 \pm 0.9 \mathrm{~b}$ & $21.2 \pm 0.2 \mathrm{~b}$ \\
\hline 3 & $6.0 \pm 0.0 \mathrm{c}$ & $7.0 \pm 0.0 \mathrm{bc}$ & $23.1 \pm 3.3 \mathrm{~b}$ & $30.6 \pm 2.6 \mathrm{a}$ \\
\hline 4 & $5.0 \pm 0.1 \mathrm{~d}$ & $7.0 \pm 0.0 \mathrm{bc}$ & $28.0 \pm 4.1 \mathrm{~b}$ & $33.0 \pm 3.3 \mathrm{a}$ \\
\hline 5 & $4.6 \pm 0.3 \mathrm{~d}$ & $7.0 \pm 0.0 \mathrm{~b}$ & $35.7 \pm 2.6 \mathrm{a}$ & $32.7 \pm 2.5 \mathrm{a}$ \\
\hline $\mathrm{S}_{1}{ }^{\mathrm{c}}$ & $135.5 * * * \mathrm{e}$ & & 0.8 & \\
\hline $\mathrm{D}_{1}{ }^{\mathrm{d}}$ & $148.2^{* * *}$ & & $161.5^{* * *}$ & \\
\hline $\mathrm{S}_{1} \times \mathrm{D}_{1}$ & $90.4^{* * *}$ & & 0.0 & \\
\hline
\end{tabular}

Table 2. Soluble $\mathrm{P}$ concentrations and $\mathrm{pH}$ of medium containing A. niger and Acinetobacter $\mathrm{sp}$. with lecithin as a $\mathrm{P}$ source during five-days incubation. ${ }^{\mathrm{a}}$ Data were listed as mean \pm S.E. ${ }^{b}$ Values followed by different letter (a-d) in the column are significantly different according to a Duncan's Multiple Range Test at $\mathrm{P}<0.05 .{ }^{c} \mathrm{~S}_{1}$, different inoculation treatments. ${ }^{\mathrm{d}} \mathrm{D}_{1}$, different incubation times (5 days). ${ }^{e * * *}$, significantly different according to a two-way ANOVA at the $0.1 \%$ level with F value.

Changes in phosphatase activity in the PSMs. Both A. niger and Acinetobacter exhibited acid and alkaline phosphatase activities (Fig. 2). Alkaline phosphatase activity was significantly higher than acid phosphatase activity in both $A$. niger and Acinetobacter sp.

The maximum acid phosphatase activity was slightly lower in A. niger than in Acinetobacter, reaching 8563.0 $\mu \mathrm{mol} \mathrm{L} \mathrm{L}^{-1} \mathrm{~h}^{-1}$ after five-days incubation (Fig. 2A). The acid phosphatase activity of $A$. niger was significantly higher after the third day of incubation. The alkaline phosphatase activity for A. niger increased rapidly, with the highest activity $\left(18,990.1 \mu \mathrm{mol} \mathrm{L}^{-1} \mathrm{~h}^{-1}\right)$ detected on the fourth day of incubation (Fig. 2B). The average acid and alkaline phosphatase activities for $A$. niger were 6951.1 and $16,152.8 \mu \mathrm{mol} \mathrm{L}^{-1} \mathrm{~h}^{-1}$, respectively, during the incubation period.

In Acinetobacter sp., the highest acid phosphatase activity (i.e., $9300.0 \mu \mathrm{mol} \mathrm{L}^{-1} \mathrm{~h}^{-1}$ ) was detected on the fourth day of culture (Fig. 2A). By contrast, the alkaline phosphatase activity of Acinetobacter sp. rapidly peaked at $16,874.1 \mu \mathrm{mol} \mathrm{L}{ }^{-1} \mathrm{~h}^{-1}$ on the second day of culture and gradually decreased thereafter (Fig. $2 \mathrm{~B}$ ). However, acid phosphatase activity was relatively steady. The average acid and alkaline phosphatase activities of Acinetobacter were 7803.7 and $13,398.5 \mu \mathrm{mol} \mathrm{L}^{-1} \mathrm{~h}^{-1}$, respectively. 

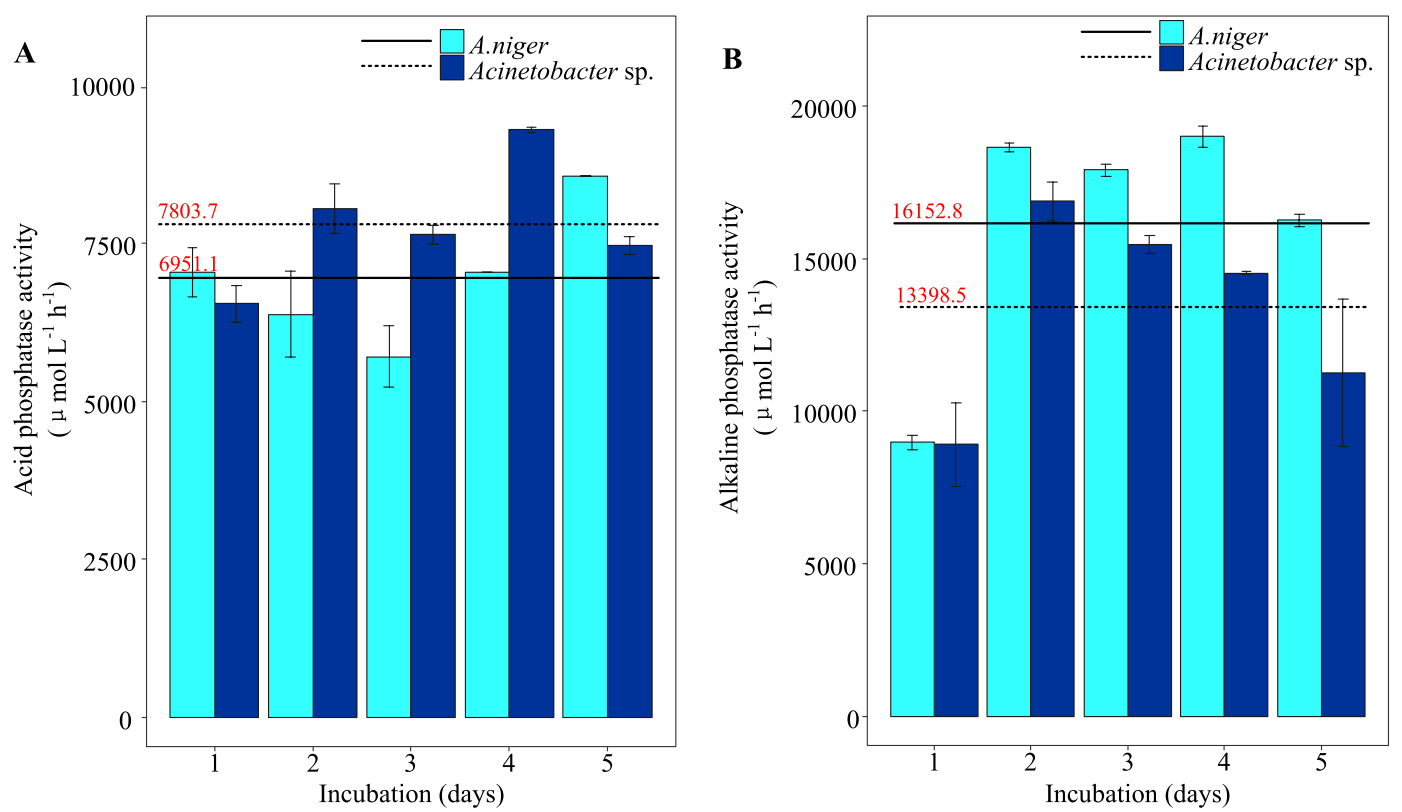

Figure 2. Dynamic changes in acid phosphatase $(\mathbf{A})$ and alkaline phosphatase $(\mathbf{B})$ activity in lecithin-amended PVK medium inoculated with $A$. niger and Acinetobacter sp. during a 5-day incubation period. The X-axis represents the days of incubation, and the Y-axis represents the enzyme activity level (phosphatase activity expressed in $\mu \mathrm{mol} \mathrm{L} \mathrm{L}^{-1} \mathrm{~h}^{-1}$ ). The solid lines represent the average enzyme activity of $A$. niger, and the dash lines represent the average enzyme activity of Acinetobacter sp.
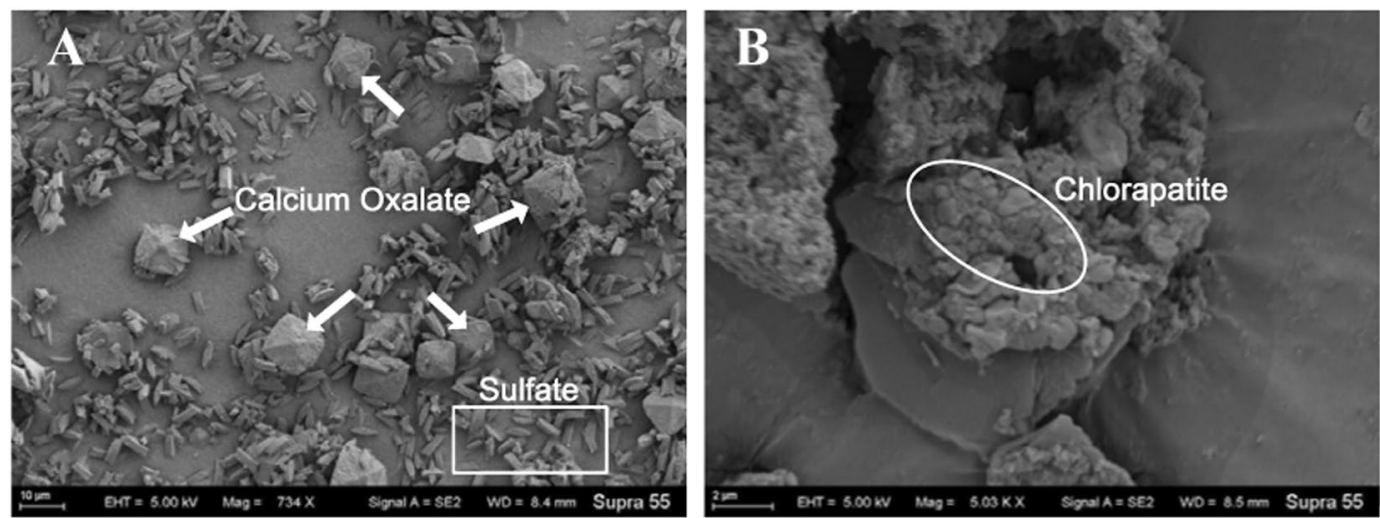

Figure 3. SEM images of precipitates formed after the addition of $\mathrm{CaCl}_{2}$ from supernatants of $A$. niger (A) and Acinetobacter sp. (B) cultures in lecithin medium after 5 days of incubation. The arrows and rectangle indicate the main forms of precipitates in A. niger, and the oval indicates the main form of precipitate in Acinetobacter sp.

Pearson's correlation analysis revealed that the soluble $\mathrm{P}$ concentration was positively association with alkaline phosphatase activity for both $A$. niger $\left(\mathrm{R}^{2}=0.3, \mathrm{P}<0.05\right)$ and Acinetobacter $\left(\mathrm{R}^{2}=0.2, \mathrm{P}<0.05\right)$. There was also a significant positive correlation between acid phosphatase activity and soluble $\mathrm{P}$ concentration in Acinetobacter $\left(\mathrm{R}^{2}=0.3, \mathrm{P}<0.05\right)$; however, this correlation was not significant in A. niger.

P mineralisation by Ca cations. Precipitates formed in the supernatants of A. niger and Acinetobacter cultures after incubation in lecithin, followed by the addition of $\mathrm{CaCl}_{2}$ (Fig. 3). In A. niger, the crystals showed a dipyramidal-prismatic shape, with sizes ranging from 2 to $10 \mu \mathrm{m}$ (Fig. 3A). These crystals were likely composed of calcium oxalate based on their morphology, according to Li et al. ${ }^{34}$. EDS indicated that the major elements in the dipyramidal-prismatic crystals from $A$. niger were $\mathrm{Ca}, \mathrm{C}$, and $\mathrm{O}$ (Fig. S1A), confirming that they were composed of calcium oxalate ${ }^{34,43}$. We also observed many tandem rhomboid-like crystals in the precipitates. These crystals were likely sulphate minerals, as $\mathrm{SO}_{4}{ }^{2-}$ is present in $\mathrm{PVK}$ medium ${ }^{44}$.

The precipitates from Acinetobacter sp. included large aggregates (Fig. 3B), which were markedly different from the particles in A. niger shown in Fig. 3A. Higher-resolution imaging of the precipitates showed that these particles were primarily spherical and spheroidal. These shapes are identical to those of nano-chlorapatite ${ }^{45}$. The aggregated appearance of the particles could be attributed to aggregation during freeze-drying of the 
precipitates ${ }^{45}$. EDS further confirmed the abundance of $\mathrm{Ca}, \mathrm{Cl}$, and $\mathrm{P}$ on the surfaces of these particles, which are the major components of chlorapatite (Fig. S1B).

\section{Discussions}

A. niger was able to secrete abundant LMWOAs to solubilize inorganic phosphates (Table 1 and Fig. 1). However, the ability of Acinetobacter sp. to break down OP (by phosphatase) was comparable to that of $A$. niger when using lecithin as a model OP compound (Table 2 and Fig. 2). Furthermore, to achieve $\mathrm{P}$ removal, the addition of $\mathrm{CaCl}_{2}$ to lecithin medium caused mineralization of the released P. However, the stable mineral chlorapatite only successfully formed in Acinetobacter sp. medium depleted of $\mathrm{P}$ (released from lecithin).

A. niger and Acinetobacter sp. secreted LMWOAs such as oxalic and formic acids, which solubilized inorganic phosphates at varying degrees (Fig. 1). These results are consistent with previous literature ${ }^{34,46,47}$. The greater ability of $A$. niger to solubilize phosphates could be attributed to the production of oxalic acid, as oxalic acid $\left(\mathrm{pK}_{\mathrm{a}}=1.4\right)$ is a strongly acidic LMWOA ${ }^{34,48,49}$. Additionally, oxalic acid can form secondary precipitates with the $\mathrm{Ca}^{2+}$ released from TCP and FAp, i.e., calcium oxalate. This results in lower concentrations of oxalic acid in A. niger. By contrast, the ability of Acinetobacter sp. to solubilize inorganic phosphate is primarily mediated by weak formic acid.

Phosphatase is an important extracellular enzyme in OP breakdown and plant P acquisition ${ }^{2,6,7,50,51}$. Acinetobacter exhibited higher acid phosphatase activity than $A$. niger during the 3 days in the middle of the incubation period (Fig. 2A). Acinetobacter sp. also showed considerable alkaline phosphatase activity, although it was lower than that of $A$. niger (Fig. 2B). Meanwhile, the soluble $\mathrm{P}$ concentration was higher in medium containing Acinetobacter versus $A$. niger beginning on the third day of incubation (Table 2). In addition, the $\mathrm{pH}$ levels of the culture medium of $A$. niger and Acinetobacter sp. were similar to the optimum pH (6.5) for acid phosphatase. Therefore, the contrast of the secretion of acid phosphatase might cause such difference of P release. Alkaline phosphatase is also highly efficient in OP decomposition, as reported in studies regarding sludge, but more active in alkaline environment ${ }^{52}$. Therefore, even the alkaline phosphatase could contribute to lecithin breakdown, but cannot exert its ideal function in this study.

Apatite is a stable P-containing mineral ${ }^{53,54}$. Here, chlorapatite, a variety of apatite, formed more readily in the supernatant from Acinetobacter sp. than from A. niger when cultured in the presence of $\mathrm{CaCl}_{2}(\mathrm{Fig}$. $3 \mathrm{~A})$. However, A. niger failed to help form chlorapatite, as this compound does not form readily in an acidic environment, according to Eq. $(1)^{45,55}$. The $\mathrm{pH}$ of $A$. niger was significantly lower than that of Acinetobacter sp. after incubation (Table 1 ). $\mathrm{Cl}^{-}$promotes pyromorphite formation at soluble $\mathrm{P}$ concentrations greater than approximately $10^{-12}$ $\mathrm{mM}$, especially in a neutral environment ${ }^{44}$. Thus, stable chlorapatite could form in a $\mathrm{Ca}^{2+}-\mathrm{PO}_{4}{ }^{3-}-\mathrm{Cl}^{-}$solution system in a neutral environment according to Eq. (2). Moreover, high levels of calcium oxalate were detected in $A$. niger, confirming that $A$. niger secretes oxalic acid, resulting in a drop in the $\mathrm{pH}$ of the medium (Fig. 3B). Therefore, Acinetobacter sp. are more suitable than A. niger in OP pollutant remediation under neutral conditions, as these conditions favour P precipitation ${ }^{56}$.

$$
\begin{gathered}
\mathrm{Ca}_{5}\left(\mathrm{PO}_{4}\right)_{3} \mathrm{Cl}+6 \mathrm{H}^{+} \rightarrow 5 \mathrm{Ca}^{2+}+3 \mathrm{H}_{2} \mathrm{PO}_{4}{ }^{-}+\mathrm{Cl}^{-} \\
5 \mathrm{Ca}^{2+}+3 \mathrm{PO}_{4}{ }^{3-}+\mathrm{Cl}^{-} \rightarrow \mathrm{Ca}_{5}\left(\mathrm{PO}_{4}\right)_{3} \mathrm{Cl} \downarrow
\end{gathered}
$$

Many OP removal techniques, such as UV-LED/TiO 2 photocatalytic (PC) and photoelectrocatalytic (PEC) technology, were usually high-cost ${ }^{9}$. In addition, the removal techniques of inorganic $\mathrm{P}$, such as $\mathrm{P}$ adsorptions by bauxite residue and ferric chloride, could induce side effects to aquatic organisms ${ }^{57,58}$. The typical PSB, Acinetobacter, is a beneficial plant growth-promoting microorganism, and widely present in water bodies and soil ${ }^{24,25,59-62}$. Moreover, Acinetobacter sp. usually display a faster rate of reproduction than PSF ${ }^{44}$. Therefore, PSB could be a potential sustainable "biomaterial" in decomposing OP. Previous studies have proposed that there were several eco-friendly methods to remove the inorganic $\mathrm{P}$ by adding $\mathrm{Mg}^{2+}$ and $\mathrm{Ca}^{2+}$ to form struvite and hydroxylapatite ${ }^{13,56}$. A combination of PSB and $\mathrm{CaCl}_{2}$ successfully decreased the risk of eutrophication caused by $\mathrm{OP}$ in water bodies, and the OP degradation efficiency was about $16.5 \%$, which is comparable to that of PC and PEC techniques 9 . Furthermore, $\mathrm{Ca}^{2+}$ and $\mathrm{Cl}^{-}$are common elements in soil systems, which will not cause serious environmental pollution ${ }^{15,63,64}$.

\section{Conclusions}

This work demonstrated that Acinetobacter (PSB) has a better potential for OP removal than A. niger (PSF). A. niger and Acinetobacter sp. were equally able to decompose OP $\left(\sim 30 \mathrm{mg} \mathrm{L}^{-1}\right)$ after incubation. The ability of $A$. niger to solubilise TCP and RP was 1.9- and 4.6-fold greater than that of Acinetobacter, respectively, as it secretes a variety of LMWOAs. However, calcium oxalate was detected in the supernatant of medium inoculated with $A$. niger after the addition of $\mathrm{CaCl}_{2}$ because the environment was weakly acidic (final $\mathrm{pH}$ of 4.6). However, stable chlorapatite can be formed in the presence of $\mathrm{Ca}^{2+}$ and $\mathrm{Cl}^{-}$in a neutral solution with addition of Acinetobacter. These findings deepen our understanding of OP decomposition using PSMs.

\section{Methods}

Strain selection and medium preparation. Acinetobacter sp. (CGMCC No. 13078) was isolated from cow manure provided by Qinbang Organic Fertilizer Company in Nanjing City, Jiangsu Province, China. A. niger (CGMCC No. 15994) was isolated from fluvo-aquic soil collected from fallow farmland in the upper $20 \mathrm{~cm}$ of soil in Nanjing, Jiangsu Province, China $\left(118^{\circ} 66^{\prime} \mathrm{E}, 31^{\circ} 92^{\prime} \mathrm{N}\right)$ in April, 2017. Pikovskaya (PVK) medium (initial $\mathrm{pH}=7.0$ ) was used to determine the ability of $A$. niger and Acinetobacter sp. to solubilize inorganic phosphates ${ }^{65,66}$. 
The main components of PVK medium are $10.0 \mathrm{~g} / \mathrm{L}$ glucose, $0.5 \mathrm{~g} / \mathrm{L}\left(\mathrm{NH}_{4}\right) \mathrm{SO}_{4}, 0.03 \mathrm{~g} / \mathrm{L} \mathrm{MnSO}_{4} \cdot 4 \mathrm{H}_{2} \mathrm{O}, 0.3 \mathrm{~g} / \mathrm{L}$ $\mathrm{KCl}, 0.3 \mathrm{~g} / \mathrm{L} \mathrm{MgSO}_{4} \cdot 7 \mathrm{H}_{2} \mathrm{O}, 0.03 \mathrm{~g} / \mathrm{L} \mathrm{FeSO}_{4} \cdot 7 \mathrm{H}_{2} \mathrm{O}, 0.3 \mathrm{~g} / \mathrm{L} \mathrm{NaCl}$, and $10 \mathrm{~g} / \mathrm{L} \mathrm{P}$ source. The levels of soluble $\mathrm{P}$ released by the two PSMs in PVK medium amended with $10 \mathrm{~g}$ tricalcium phosphate (TCP) (Nanjing Reagent Co. Ltd. of China, AR) or $10 \mathrm{~g}$ fluorapatite (FAp) (Taizhou Chemical Fertilizer Plant of China) as a P source after five-days incubation (Table 1). All experiments were performed with triplicate.

Acinetobacter was cultured in Luria-Bertani liquid medium, and A. niger was cultured in potato dextrose agar (PDA) medium. Acinetobacter sp. suspensions were collected by centrifugation at $16,099.2 \mathrm{~g}\left(4^{\circ} \mathrm{C}\right)$ for $2 \mathrm{~min}$. A. niger spore suspensions were collected by washing the spores on the surface of spore-forming PDA medium repeatedly with sterile water and filtering them through six types of gauze into an aseptic flask, according to the modified methods of Ren et al. ${ }^{67}$. Bacterial cells and fungal spores were adjusted to approximately $1 \times 10^{8} \mathrm{CFU}$ per $\mathrm{mL}$ using a haemocytometer.

Detection of organic acid secreted by PSMs. To detect the LMWOAs secreted by PSMs, high-performance liquid chromatography (HPLC, Agilent 1260, USA) was used. For each sample, $2 \mathrm{~mL}$ of medium was collected from cultures in inorganic phosphate (for both TCP and FAp-amended PVK medium) after five-days of incubation. All samples were filtered through a $0.22-\mu \mathrm{m}$ membrane prior to analysis. An RP-C chromatographic column $(250 \mathrm{~mm} \times 4.6 \mathrm{~mm}, 5 \mu \mathrm{m}$, Shimadzu, Japan $)$ was used with a temperature of $30^{\circ} \mathrm{C}$. The mobile phase was $2.5 \%\left(\mathrm{NH}_{4}\right) \mathrm{H}_{2} \mathrm{PO}_{4}$ ( $\mathrm{pH}$ adjusted to 2.5 with phosphoric acid) with the chromatographic reagent methyl alcohol at the ratio of 99:1. The flow rate was controlled at $0.5 \mathrm{~mL} \mathrm{~min}^{-1}$, and the wavelength of detector was $210 \mathrm{~nm}$.

Quantifying the ability to breakdown lecithin. The ability of the PSMs to break down lecithin was quantified in the PVK medium amended with lecithin $\left(0.2 \mathrm{~g} \mathrm{P} \mathrm{L}^{-1}\right)$. A shaking culture experiment was then conducted using both PSMs. First, $1 \%$ suspensions $\left(\mathrm{OD}_{600}=0.5\right)$ were inoculated into $50 \mathrm{~mL}$ lecithin-amended medium in triplicate. The cultures were shaken at $180 \mathrm{rpm}$ at $30^{\circ} \mathrm{C}$ for 5 days. During the incubation, $3-\mathrm{mL}$ samples were collected daily under aseptic conditions and used to measure medium $\mathrm{pH}$ and soluble $\mathrm{P}$ concentration. The $\mathrm{pH}$ of the medium was then measured by a pH meter (FE 20, Mettler, German). The soluble P concentration was measured using the molybdate blue method and quantified spectrophotometrically at an absorbance wavelength of $880 \mathrm{~nm}$.

To detect acid and alkaline phosphatase secreted by the PSMs during incubation, enzyme activity was analyzed using the disodium phenyl phosphate method (DPP) ${ }^{68}$. Briefly, $1 \mathrm{~mL}$ fermented lecithin medium was incubated with $4 \mathrm{~mL}$ universal buffer $(\mathrm{pH}=6.5$ for acid phosphatase and $\mathrm{pH}=11$ for alkaline phosphatase) and $1 \mathrm{~mL}$ $25 \mathrm{mM}$ DPP for $1 \mathrm{~h}$ at $37^{\circ} \mathrm{C}$. Subsequently, $1 \mathrm{~mL} 0.5 \mathrm{M} \mathrm{CaCl}_{2}$ and $4 \mathrm{ml} 0.5 \mathrm{M} \mathrm{NaOH}$ were added to terminate the reaction. The concentration of DPP was measured spectrophotometrically based on absorbance at $510 \mathrm{~nm}$.

Measurement of $\mathrm{CaCl}_{2}$ precipitation. Lecithin medium inoculated with the PSMs and incubated for 5 days was centrifuged at $16,099.2 \mathrm{~g}\left(4^{\circ} \mathrm{C}\right)$ for $10 \mathrm{~min}$ to remove the microorganisms and insoluble residues. The supernatant was collected into a new flask. A rotary evaporator was used to concentrate the supernatant and increase the concentration of soluble $\mathrm{P} . \mathrm{CaCl}_{2}$ (Nanjing Reagent Co. Ltd. of China, AR) was added to the supernatant at a $\mathrm{Ca} / \mathrm{P}$ molar ratio of 100:1.

To achieve complete precipitation, the supernatant was shaken at $180 \mathrm{rpm}$ at $30^{\circ} \mathrm{C}$ for $1 \mathrm{~h}$. The precipitates were collected by filtering through a $0.22-\mu \mathrm{m}$ membrane and washed twice with sterile water to remove the liquid residue. To obtain dry powered samples, the precipitates were lyophilised at $-40^{\circ} \mathrm{C}$ for $24 \mathrm{~h}$.

Statistical analysis. Duncan's multiple range test was used to analyse the differences between treatments. Two-way ANOVA and Fisher's test were used to evaluate the $\mathrm{pH}$ and soluble $\mathrm{P}$ concentration of the medium after different periods of culture with different PSMs. All differences were considered to be significant at $\mathrm{P}<0.05$. All statistical analysis was conducted using $\mathrm{R}$ software version 3.3.2 $2^{69}$.

Received: 22 January 2019; Accepted: 4 October 2019;

Published online: 25 October 2019

\section{References}

1. Mezeli, M. M. et al. Effect of citrate on Aspergillus niger phytase adsorption and catalytic activity in soil. Geoderma. 305, 346-353 (2017).

2. Feng, G., Song, Y. C., Li, X. L. \& Christie, P. Contribution of arbuscular mycorrhizal fungi to utilization of organic sources of phosphorus by red clover in a calcareous soil. Appl. Soil Ecol. 22(2), 139-148 (2003).

3. Bünemann, E. K. Assessment of gross and net mineralization rates of soil organic phosphorus - A review. Soil Biol. Biochem. 89, 82-98 (2015).

4. Amini, N. \& McKelvie, I. An enzymatic flow analysis method for the determination of phosphatidylcholine in sediment pore waters and extracts. Talanta. 66(2), 445-452 (2005).

5. Zhao, G. Y. et al. The importance of bacteria in promoting algal growth in eutrophic lakes with limited available phosphorus. Ecol. Eng. 42, 107-111 (2012).

6. Della Monica, I. F., Godoy, M. S., Godeas, A. M. \& Scervino, J. M. Fungal extracellular phosphatases: their role in P cycling under different $\mathrm{pH}$ and $\mathrm{P}$ sources availability. J. Appl. Microbiol. 124(1), 155-165 (2018).

7. Cabugao, K. G. et al. Root and rhizosphere bacterial phosphatase activity varies with tree species and soil phosphorus availability in Puerto Rico tropical forest. Front. Plant. Sci. 8, 1834 (2017).

8. Dalrymple, O. K., Isaace, W., Stefanakos, E., Trotz, M. A. \& Goswami, D. Y. Lipid vesicles as model membranes in photocatalytic disinfection studies. J. Photoch. Photobio. A. 221(1), 64-70 (2011)

9. Li, G. Y., Liu, X. L., An, T. C., Wong, P. K. \& Zhao, H. J. A novel method developed for estimating mineralization efficiencies and its application in PC and PEC degradations of large molecule biological compounds with unknown chemical formula. Water Res. 95, 150-158 (2016) 
10. Trinh, H. N., Tran, L. H., Lee, C. \& Jang, S. H. Lipid hydrolysis catalyzed by graphene oxide. B. Kor. Chem. Soc. 38(12), 1455-1459 (2017).

11. Urano, K., Tachikawa, H. \& Kitajima, M. Process-development for removal and recovery of phosphorus from waste-water by a new adsorbent recovery of phosphate and aluminum from desorbing solution. Ind. Eng. Chem. Res. 31(6), 1513-1515 (1992).

12. Mohara, G. et al. Phosphorus recovery from wastewater treatment plant by using waste concretes. J. Chem. Eng. Jpn. 44(1), 48-55 (2011).

13. Okano, K. et al. H. Novel technique for phosphorus recovery from aqueous solutions using amorphous calcium silicate hydrates (A-CSHs). Water Res. 47(7), 2251-2259 (2013).

14. Capdevielle, A., Sykorova, E., Beline, F. \& Daumer, M. L. Effects of organic matter on crystallization of struvite in biologically treated swine wastewater. Environ. Technol. 37(7), 880-892 (2016).

15. Nur, T., Loganathan, P., Kandasamy, J. \& Vigneswaran, S. Phosphate Adsorption from membrane bioreactor effluent using dowex $21 \mathrm{~K} \mathrm{XLT}$ and recovery as struvite and hydroxyapatite. Int. J. Environ. Res. Public Health. 13 (3) (2016).

16. Li, Z. et al. Characterizing the mechanisms of lead Immobilization via bioapatite and various clay minerals. ACS Earth and Space Chem. 1(3), 152-157 (2017).

17. Pereira, S. I. A. \& Castro, P. M. L. Phosphate-solubilizing rhizobacteria enhance Zea mays growth in agricultural P-deficient soils. Ecol. Eng. 73, 526-535 (2014).

18. Brigido, C., Glick, B. R. \& Oliveria, S. Survey of plant growth-promoting mechanisms in native portuguese chickpea Mesorhizobium isolates. Microb. Ecol. 73(4), 900-915 (2017).

19. Hayat, W. et al. Analysis of ecological attributes of bacterial phosphorus solubilizers, native to pine forests of Lower Himalaya. Appl. Soil Ecol. 112, 51-59 (2017).

20. Yadav, H., Fatima, R., Sharma, A. \& Mathur, S. Enhancement of applicability of rock phosphate in alkaline soils by organic compost. Appl. Soil Ecol. 113, 80-85 (2017).

21. Vazquez, P., Holguin, G., Puente, M. E., Lopez-Cortes, A. \& Bashan, Y. Phosphate-solubilizing microorganisms associated with the rhizosphere of mangroves in a semiarid coastal lagoon. Biol. Fert. Soils. 30(5-6), 460-468 (2000).

22. Gyaneshwar, P., Kumar, G. N., Parekh, L. J. \& Poole, P. S. Role of soil microorganisms in improving P nutrition of plants. Plant Soil. 245(1), 83-93 (2002).

23. Kavanagh, K. Fungi: Biology and Applications (Wiley, U. S., 2005).

24. Kang, S. M. et al. Gibberellin production and phosphate solubilization by newly isolated strain of Acinetobacter calcoaceticus and its effect on plant growth. Biotechnol. Lett. 31(2), 277-281 (2009).

25. Ogut, M., Er, F. \& Kandemir, N. Phosphate solubilization potentials of soil Acinetobacter strains. Biol. Fert. Soils. 46(7), 707-715 (2010).

26. Shahid, M. et al. Characterization of mineral phosphate-solubilizing bacteria for enhanced sunflower growth and yield-attributing traits. Ann. Microbiol. 65(3), 1525-1536 (2014).

27. Liu, Z. G. et al. Characterization of phosphate-solubilizing bacteria isolated from calcareous soils. Appl. Soil Ecol. 96, 217-224 (2015).

28. Ludueña, L. M. et al. Role of bacterial pyrroloquinoline quinone in phosphate solubilizing ability and in plant growth promotion on strain Serratia sp. S119. Symbiosis. 72(1), 31-43 (2016).

29. Ogbo, F. C. Conversion of cassava wastes for biofertilizer production using phosphate solubilizing fungi. Bioresour. Technol. 101(11), 4120-4124 (2010).

30. Priyadharsini, P. \& Muthukumar, T. The root endophytic fungus Curvularia geniculata from Parthenium hysterophorus roots improves plant growth through phosphate solubilization and phytohormone production. Fungal Ecol. 27, 69-77 (2017).

31. Saxena, J., Minaxi \& Jha, A. Impact of a phosphate solubilizing bacterium and an arbuscular mycorrhizal fungus (Glomus etunicatum) on growth, yield and P concentration in wheat plants. CLEAN - Soil Air Water. 42(9), 1248-1252 (2014).

32. Ceci, A., Pinzari, F., Russo, F., Maggi, O. \& Persiani, A. M. Saprotrophic soil fungi to improve phosphorus solubilisation and release: In vitro abilities of several species. Ambio. 47(Suppl 1), 30-40 (2018).

33. Li, X. L., Luo, L. J., Yang, J. S., Li, B. Z. \& Yuan, H. L. Mechanisms for solubilization of various insoluble phosphates and activation of immobilized phosphates in different soils by an efficient and salinity-tolerant Aspergillus niger strain An2. Appl. Biochem. Biotechnol. 175(5), 2755-2768 (2015).

34. Li, Z. et al. Lead immobilization by geological fluorapatite and fungus Aspergillus niger. J. Hazard Mater. 320, 386-392 (2016).

35. Gaind, S. \& Nain, L. Soil phosphorus mobilization potential of phytate mineralizing fungi. J. Plant Nutr. 38(14), 2159-2175 (2015).

36. Iyer, B., Rajput, M. S. \& Rajkumar, S. Effect of succinate on phosphate solubilization in nitrogen fixing bacteria harbouring chick pea and their effect on plant growth. Microbiol. Res. 202, 43-50 (2017).

37. Reichert, C. L., Salminen, H., Bonisch, G. B., Schafer, C. \& Weiss, J. Concentration effect of Quillaja saponin - Co-surfactant mixtures on emulsifying properties. J. Colloid Interface Sci. 519, 71-80 (2018).

38. Arelli, A. et al. Optimization of washing conditions with biogenic mobilizing agents for marine fuel-contaminated beach sands. New Biotechnol. 43, 13-22 (2018).

39. Manahan, S. E. Environmental Chemistry, 6th ed. (Lewis Publishers, Michigan, 1994).

40. Gao, G., Zhu, G. W., Qin, B. Q., Chen, J. \& Wang, K. Alkaline phosphatase activity and the phosphorus mineralization rate of Lake Taihu. Sci. China Ser. D. 49, 176-185 (2006).

41. Guzey, D. \& McClements, D. J. Formation, stability and properties of multilayer emulsions for application in the food industry. $A d v$. Colloid Interfac. 128, 227-248 (2006).

42. Dammak, I. \& Sobral, P. J. D. Investigation into the physicochemical stability and rheological properties of rutin emulsions stabilized by chitosan and lecithin. J. Food Eng. 229, 12-20 (2018).

43. Sturm, E. V. et al. Crystallization of calcium oxalate hydrates by interaction of calcite marble with fungus Aspergillus niger. Am. Mineral. 100(11-12), 2559-2565 (2015).

44. Li, Z. et al. Induced biotransformation of lead (II) by Enterobacter sp. in $\mathrm{SO}_{4}-\mathrm{PO}_{4}-\mathrm{Cl}$ solution. J. Hazard Mater. 357, $491-497$ (2018).

45. Wan, J. et al. Rhamnolipid stabilized nano-chlorapatite: Synthesis and enhancement effect on $\mathrm{Pb}$ - and Cd-immobilization in polluted sediment. J. Hazard Mater. 343, 332-339 (2018).

46. Kumar, C., Yadav, K., Archana, G. \& Kumar, G. N. 2-ketogluconic acid secretion by incorporation of Pseudomonas putida KT 2440 gluconate dehydrogenase ( $\mathrm{gad}$ ) operon in Enterobacter asburiae PSI3 improves mineral phosphate solubilization. Curr. Microbiol. 67(3), 388-394 (2013).

47. Tian, D. et al. A new insight into lead (II) tolerance of environmental fungi based on a study of Aspergillus niger and Penicillium oxalicum. Environ. Microbiol. 21(1), 471-479 (2019).

48. Akintokun, A. K., Akande, G. A., Akintokun, P. O., Popoola, T. O. S. \& Babalola, A. O. Solubilization of insoluble phosphate by organic acid-producing fungi isolated from Nigerian soil. Int. J. Soil Sci. 2(4), 301-307 (2007).

49. Faraji, F., Golmohammadzadeh, R., Rashchi, F. \& Alimardani, N. Fungal bioleaching of WPCBs using Aspergillus niger: Observation, optimization and kinetics. J. Environ. Manage. 217, 775-787 (2018),

50. Tarafdar, J. C., Yadav, R. S. \& Meena, S. C. Comparative efficiency of acid phosphatase originated from plant and fungal sources. J. Plant Nutr. Soil Sci. 164(3), 279-282 (2001).

51. Cernusak, L. A. et al. Tropical forest responses to increasing atmospheric $\mathrm{CO}_{2}$ : current knowledge and opportunities for future research. Funct. Plant Biol. 40(6), 531-551 (2013).

52. Xie, C. et al. The phosphorus fractions and alkaline phosphatase activities in sludge. Bioresour. Technol. 102(3), 2455-2461 (2011).

53. Ma, Q. Y., Traina, S. J., Logan, T. J. \& Ryan, J. A. In-situ lead immobilization by apatite. Environ. Sci. Technol. 27(9), 1803-1810 (1993).

54. Chen, W. K. et al. Temperature-related changes of $\mathrm{Ca}$ and $\mathrm{P}$ release in synthesized hydroxylapatite, geological fluorapatite, and bone bioapatite. Chem. Geol. 451, 183-188 (2017). 
55. Yan, Y. B. et al. Removal of phosphate from wastewater using alkaline residue. J. Environ. Sci.-China. 26(5), 970-980 (2014).

56. Zeng, F. et al. Struvite precipitation from anaerobic sludge supernatant and mixed fresh/stale human urine. Chemical Engineering Journal 344, 254-261 (2018).

57. Moore, P. A. \& Miller, D. M. Decreasing phosphorus solubility in poultry litter with aluminum, calcium, and iron amendments. J. Environ. Qual. 23, 325-330 (1994).

58. Cusack, P. B. et al. The use of rapid, small-scale column tests to determine the efficiency of bauxite residue as a low-cost adsorbent in the removal of dissolved reactive phosphorus from agricultural waters. Journal of Environmental Management 241, 273-283 (2019).

59. Abbasi, M. K., Musa, N. \& Manzoor, M. Mineralization of soluble P fertilizers and insoluble rock phosphate in response to phosphate-solubilizing bacteria and poultry manure and their effect on the growth and $\mathrm{P}$ utilization efficiency of chilli (Capsicum annuum L.). Biogeosciences. 12(15), 4607-4619 (2015).

60. Liu, F. P. et al. Isolation and characterization of phosphate-solubilizing bacteria from betel nut (Areca catechu) and their effects on plant growth and phosphorus mobilization in tropical soils. Biol. Fert. Soils. 50(6), 927-937 (2014).

61. Zaidi, A. et al. Growth stimulation and management of diseases of ornamental plants using phosphate solubilizing microorganisms: current perspective. Acta Physiol. Plant. 38(5), 117 (2016).

62. de-Bashan, L. E. \& Bashan, Y. Recent advances in removing phosphorus from wastewater and its future use as fertilizer (1997-2003). Water Res. 38(19), 4222-4246 (2004).

63. Morse, G. K., Brett, S. W., Guy, J. A. \& Lester, J. N. Review: Phosphorus removal and recovery technologies. Sci. Total Environ. 212(1), 69-81 (1998).

64. Rittmann, B. E., Mayer, B., Westerhoff, P. \& Edwards, M. Capturing the lost phosphorus. Chemosphere. 84(6), 846-853 (2011).

65. Pikovskaya, R. I. Mobilization of phosphorous in soil in connection with vital activity of some microbial species. Mikrobiologya. 17, 362-370 (1948)

66. Oliveira, C. A. et al. Phosphate solubilizing microorganisms isolated from rhizosphere of maize cultivated in an oxisol of the Brazilian Cerrado Biome. Soil Biol. Biochem. 41(9), 1782-1787 (2009).

67. Ren, N. et al. Identification of vincamine indole alkaloids producing endophytic fungi isolated from Nerium indicum, Apocynaceae. Microbiol. Res. 192, 114-121 (2016).

68. Behera, B. C. et al. Phosphate solubilization and acid phosphatase activity of Serratia sp. isolated from mangrove soil of Mahanadi river delta, Odisha, India. J. Genetic Eng. Biotechnol. 15(1), 169-178 (2017).

69. R Core Team. R: A language and environment for statistical computing, R Foundation for Statistical Computing (Vienna, Austria, 2016).

\section{Acknowledgements}

Our research was kindly supported by Jiangsu Agriculture Science and Technology Innovation Found (JASTIF) [CX(17)1001] and National Key Research and Development Program of China (2016YFD0300908). Furthermore, we sincerely thank Da Tian and Lin Zhang for the assistance in this work, we also sincerely thank Kathy and Plant Editors team for the language polish and logic modification.

\section{Author contributions}

Chunkai Li, Zhen Li and Jiaguo Jiao wrote the main manuscript text. Zhen Li and Huixin Li were responsible for the experimental design and guidance. Chunkai Li and Guanning Ji contributed to phosphate-solubilizing microorganism isolation, soluble $\mathrm{P}$ releasing ability determination and phosphatase activity assay. Chunkai $\mathrm{Li}, \mathrm{He}$ Zhao and Fei Gao determined organic acids concentration by HPLC. Chunkai Li and Mu Su contributed to SEM analysis and EDS analysis. Qisheng Li and Zhipeng Wang contributed to check of images and tables. All authors reviewed the manuscript.

\section{Competing interests}

The authors declare that they have no competing interests or other interests that might be perceived to influence the results and/or discussion reported in this paper.

\section{Additional information}

Supplementary information is available for this paper at https://doi.org/10.1038/s41598-019-51804-7.

Correspondence and requests for materials should be addressed to J.J. or Z.L.

Reprints and permissions information is available at www.nature.com/reprints.

Publisher's note Springer Nature remains neutral with regard to jurisdictional claims in published maps and institutional affiliations.

(c) (i) Open Access This article is licensed under a Creative Commons Attribution 4.0 International

License, which permits use, sharing, adaptation, distribution and reproduction in any medium or format, as long as you give appropriate credit to the original author(s) and the source, provide a link to the Creative Commons license, and indicate if changes were made. The images or other third party material in this article are included in the article's Creative Commons license, unless indicated otherwise in a credit line to the material. If material is not included in the article's Creative Commons license and your intended use is not permitted by statutory regulation or exceeds the permitted use, you will need to obtain permission directly from the copyright holder. To view a copy of this license, visit http://creativecommons.org/licenses/by/4.0/.

(C) The Author(s) 2019 